J Arid Land (2014) 6(2): 230-242

doi: $10.1007 / \mathrm{s} 40333-013-0225-4$

jal.xjegi.com; www.springer.com/40333

\title{
Optimizing water and nitrogen inputs for winter wheat cropping system on the Loess Plateau, China
}

\author{
QiuPing FU ${ }^{1,2,3}$, QuanJiu WANG ${ }^{1,4^{*}}$, XinLei SHEN ${ }^{5}$, Jun FAN ${ }^{1,6}$ \\ ${ }^{1}$ State Key Laboratory of Soil Erosion and Dryland Farming on the Loess Plateau, Institute of Soil and Water Conservation, \\ Chinese Academy of Sciences and Ministry of Water Resources, Yangling 712100, China; \\ ${ }^{2}$ College of Hydraulic and Civil Engineering of Xinjiang Agricultural University, Urumqi 830052, China; \\ ${ }^{3}$ University of Chinese Academy of Sciences, Beijing 100049, China; \\ ${ }^{4}$ Xi'an University of Technology, Xi'an 710048, China; \\ ${ }^{5}$ Luohe Soil and Fertilizer Extension Service, Luohe 462300, China; \\ ${ }^{6}$ Northwest A\&F University, Yangling 712100, China
}

\begin{abstract}
Optimal use of water and fertilizers can enhance winter wheat yield and increase the efficiencies of water and fertilizer usage in dryland agricultural systems. In order to optimize water and nitrogen $(\mathrm{N})$ management for winter wheat, we conducted field experiments from 2006 to 2008 at the Changwu Agro-ecological Experimental Station of the Chinese Academy of Sciences on the Loess Plateau, China. Regression models of wheat yield and evapotranspiration (ET) were established in this study to evaluate the water and fertilizer coupling effects and to determine the optimal coupling domain. The results showed that there was a positive effect of water and $\mathrm{N}$ fertilizer on crop yield, and optimal irrigation and $\mathrm{N}$ inputs can significantly increase the yield of winter wheat. In the drought year (2006-2007), the maximum yield $\left(Y_{\max }\right)$ of winter wheat was $9.211 \mathrm{t} / \mathrm{hm}^{2}$ for the treatment with $324 \mathrm{~mm}$ irrigation and $310 \mathrm{~kg} / \mathrm{hm}^{2} \mathrm{~N}$ input, and the highest water use efficiency (WUE) of $16.335 \mathrm{~kg} /\left(\mathrm{hm}{ }^{2} \cdot \mathrm{mm}\right.$ ) was achieved with $198 \mathrm{~mm}$ irrigation and $274 \mathrm{~kg} / \mathrm{hm}^{2} \mathrm{~N}$ input. While in the normal year (2007-2008), the maximum winter wheat yield of $10.715 \mathrm{t} / \mathrm{hm}^{2}$ was achieved by applying $318 \mathrm{~mm}$ irrigation and $291 \mathrm{~kg} / \mathrm{hm}^{2} \mathrm{~N}$, and the highest WUE was 18.69 $\mathrm{kg} /\left(\mathrm{hm}^{2} \cdot \mathrm{mm}\right)$ with $107 \mathrm{~mm}$ irrigation and $256 \mathrm{~kg} / \mathrm{hm}^{2} \mathrm{~N}$ input. Crop yield and ET response to irrigation and $\mathrm{N}$ inputs followed a quadratic and a line function, respectively. The optimal coupling domain was determined using the elasticity index (EI) and its expression in the water- $\mathrm{N}$ dimensions, and was represented by an ellipse, such that the global maximum WUE (WUE $\left.E_{\max }\right)$ and $Y_{\max }$ values corresponded to the left and right end points of the long axis, respectively. Considering the aim to get the greatest profit in practice, the optimal coupling domain was represented by the lower half of the ellipse, with the $Y_{\max }$ and $W U E_{\max }$ on the two end points of the long axis. Overall, we found that the total amount of irrigation for winter wheat should not exceed $324 \mathrm{~mm}$. In addition, our optimal coupling domain visually reflects the optimal range of water and $\mathrm{N}$ inputs for the maximum winter wheat yield on the Loess Plateau, and it may also provide a useful reference for identifying appropriate water and $\mathrm{N}$ inputs in agricultural applications.
\end{abstract}

Keywords: water-fertilizer coupling; water use efficiency; optimal coupling domain; yield; winter wheat

Citation: QiuPing FU, QuanJiu WANG, XinLei SHEN, Jun FAN. 2014. Optimizing water and nitrogen inputs for winter wheat cropping system on the Loess Plateau, China. Journal of Arid Land, 6(2): 230-242. doi: 10.1007/s40333-013-0225-4

The unbalanced distribution of water and nutrients can significantly limit crop production (Tang, 1999; Zhu, 2000; Xie, 2001; Gao and Li, 2003). The efficient coupling of soil water and fertilizer use is, therefore, an important issue for improving the economic and ecological outcomes of crop production and ensuring the sustainable development of dryland agriculture (Hou et al., 2012).

*Corresponding author: QuanJiu WANG (E-mail: wquanjiu@163.com)

Received 2013-04-16; revised 2013-06-28; accepted 2013-07-22

(C) Xinjiang Institute of Ecology and Geography, Chinese Academy of Sciences, Science Press and Springer-Verlag Berlin Heidelberg 2014 
The coordination of soil water content, soil nutrients and their crop demand greatly influences winter wheat yield on the dry and infertile Loess Plateau in Northwest China (Sharma et al., 1992; Wang, 1995; Chen, 1996), where precipitation is scarce and unevenly distributed (Huang et al., 2002). On the plateau, over $55 \%$ of the regional rainfall occurs from July through September, while the winter wheat grows fastest during its peak growth period from April through June, which significantly inhibits fertilizer absorption. The use of large amounts of nitrogen $(\mathrm{N})$ fertilizer can significantly improve crop yield, but overuse of it can also lead to environmental problems (Guo et al., 2003). Liu et al. (2000) indicated that irrigation and fertilization can result in a high crop yield in the drought-prone and infertile regions. An appropriate irrigation scheme can significantly improve water use efficiency (WUE) and may eventually increase crop yield and conserve water resources (Li et al., 2004; Gu et al., 2012). The yield of winter wheat increases with the increasing amounts of $\mathrm{N}$ fertilizer within an appropriate range (Cai et al., 1994; Huang et al., 1999). Generally, water and fertilizer have a synergistic effect on crop growth. On the one hand, water deficiency restricts the effect of fertilizers on crop yield increasing, while too much water input also leads to a reduction of crop yield and $\mathrm{N}$ loss through leaching. On the other hand, both excessive and deficient $\mathrm{N}$ fertilizer use can limit the efficiency of water use, which in turn affects the crop yield (Tang and Yang, 1994; Zhen and Liu, 1995; Miao, 1997; Zhai and Li, 2003). In general, the amount of nutrients for a crop to produce a maximal yield varies with the variation of water inputs, and vice versa (Gajri et al., 1993; Sandhu et al., 2002). Many researches have suggested that, at fixed water inputs, the optimal inputs of fertilizer can produce a maximum crop yield; the same is true that fixed fertilizer inputs determine the optimal water inputs (Balasubramanian and Chari, 1983; Sharma et al., 1990; Shen et al., 2001). Therefore, optimizing water and fertilizer coupling levels may be the best way to improve the efficiencies of both fertilizer and water use (Zhai and $\mathrm{Li}, 2005$ ).

After Arnon (1975) proposed that the basic prob- lems of dryland agriculture are reasonable fertilizer inputs and high WUE under limited water conditions, researches on the influence of water-fertilizer coupling on crop yields were widely conducted (Balasubramanian and Chari, 1983; Sharma et al., 1990, 1992; Wang, 1995; Li et al., 2000; Liu and Zhang, 2007; Kong et al., 2008). However, the results were different by regions, crop varieties and fertilizer levels (Meng et al., 1998; Li et al., 2000; Liu et al., 2000; Shen et al., 2001; Wu et al., 2001; Li et al., 2005; Kong et al., 2008). High WUE and crop yield are two important objectives for the development of dryland agriculture. Analyzing the optimal inputs of water and fertilizer for increasing WUE and crop yield is an important issue in water-saving agriculture (Liu, 1997, 1998; Liu et al., 2002; Liu and Zhang, 2007).

The objectives of this study are to: (1) analyze the effects of water and $\mathrm{N}$ fertilizer coupling levels on winter wheat yield and the indicators associated with the yield; (2) establish regression equations to describe the relationships between crop yield, irrigation and $\mathrm{N}$ fertilizer use; and (3) determine a reasonable amount of irrigation and $\mathrm{N}$ inputs for the maximum winter wheat yield.

\section{Materials and methods}

\subsection{Study area}

Field experiments were conducted from October 2006 to June 2007 and from October 2007 to June 2008 at the Changwu Agro-ecological Experimental Station of the Chinese Academy of Sciences, which is located in a typical semi-arid area of the Loess Plateau, Shaanxi province, Northwest China $\left(107^{\circ} 40^{\prime} 30^{\prime \prime} \mathrm{E}, 35^{\circ} 14^{\prime} 30^{\prime \prime} \mathrm{N}\right.$; $1,200 \mathrm{~m}$ asl). A long-term (1956-2008) average annual precipitation in this region is $584 \mathrm{~mm}$. The annual mean temperature is $9.1^{\circ} \mathrm{C}$ and the mean annual accumulative temperature above $10^{\circ} \mathrm{C}$ is $3,029^{\circ} \mathrm{C}$. The average annual frost-free period is 171 days. Precipitation and temperature data in this study (Fig. 1) were from a weather station of Chinese Ecological Research Network, $100 \mathrm{~m}$ away from the east of the experimental site. According to the division standard for different precipitation years (Hao et al., 2003), we divided a year into two periods, i.e. the fallow period 


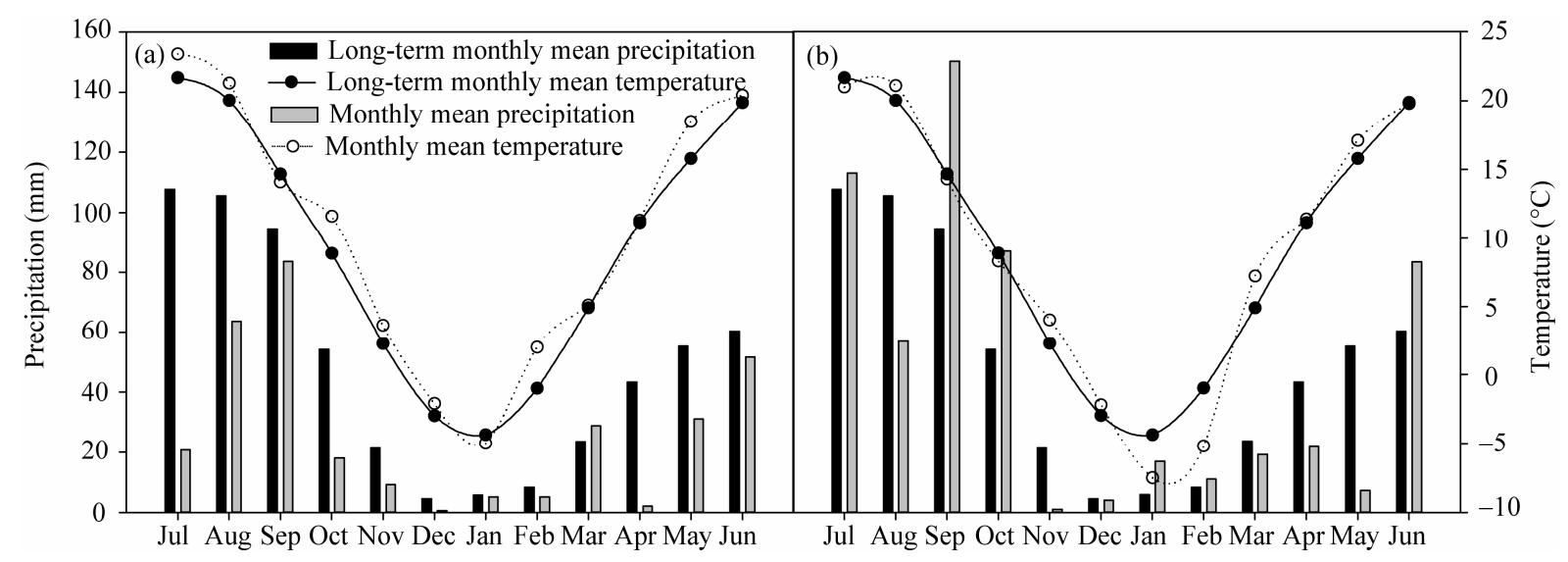

Fig. 1 Monthly mean precipitation and temperature from July 2006 to June 2007 (a) and July 2007 to June 2008 (b) compared with the long-term monthly means (1956-2008) at the experimental site

before sowing (from July through September) and the growing period (from October through the next June). The year with 'normal precipitation' is defined as the normal year, while the wet year is considered having $10 \%$ more or above precipitation compared with the long-term average, and the drought year having $10 \%$ less or below precipitation compared with the average value. During our experiments, the mean temperatures in the two growing seasons were similar and close to the long-term annual average. The precipitation from July 2006 to June 2007 was less than $10 \%$ of the long-term mean annual amount, while from July 2007 to June 2008 it approached the long-term mean value. Therefore, 2006-2007 and 2007-2008 in this study were considered to represent the drought and normal year, respectively.

The soil of the experimental site is Heilu soil (Calcic Kastanozems, FAO) with a field capacity of $23 \%$ and a permanent wilting coefficient of $10 \%$ in gravimetric content. The $\mathrm{pH}$ value of topsoil $(0-20 \mathrm{~cm})$ was 8.2. The organic matter, total $\mathrm{N}$, hydrolysable $\mathrm{N}$, available phosphorous (AP) and available potassium (AK) contents were $11.2 \mathrm{~g} / \mathrm{kg}, 0.89 \mathrm{~g} / \mathrm{kg}, 42.9 \mathrm{mg} / \mathrm{kg}$, $5.8 \mathrm{mg} / \mathrm{kg}$ and $172.6 \mathrm{mg} / \mathrm{kg}$, respectively.

\subsection{Experimental design}

The study was carried out by using an incomplete factorial design. The treatments were combinations of irrigation water and $\mathrm{N}$ application with 3 replications (Table 1). Totally, 27 treatments were assigned into 81 plots in a randomized block design. Every plot has an area of $16 \mathrm{~m}^{2}$, and was surrounded by $1-\mathrm{m}$ wide vege- tated buffer strips.

The numbers of $\mathrm{N}$ and irrigation treatments in this study were designed as arithmetic progressions. In order to facilitate the calculation, we used the numerical designators (levels) to represent the amounts of $\mathrm{N}$ and irrigation water rather than their actual quantities. The lowest level of $\mathrm{N}$ or irrigation water was expressed using the number 0 , and increasing numbers were given in the order of increasing $\mathrm{N}$ or irrigation water quantities as 1, 2, 3, 4 and 5 .

Irrigations were conducted at five growing stages of winter wheat, i.e. over-wintering, turning green, jointing, heading and filling. About $75-\mathrm{mm}$ equivalent water was piped and irrigated to every plot at every irrigation treatment. The treatment W0 $(0)$ received no irrigation at the whole growing stage, W1 $(75 \mathrm{~mm})$ received 1 irrigation at the over-wintering stage, W2 $(150 \mathrm{~mm})$ received 2 irrigations at the over-wintering and turning green stages, and so forth for W3 (225 $\mathrm{mm})$, W4 (300 mm) and W5 (375 mm; Table 1). N rates in this study were $0(\mathrm{~N} 0), 75(\mathrm{~N} 1), 150(\mathrm{~N} 2), 225$ (N3), $300(\mathrm{~N} 4)$ and 375 (N5) kg/hm², respectively. All the $\mathrm{N}$ fertilizers, in forms of urea and $120 \mathrm{~kg}$ phosphorous pentoxide $\left(\mathrm{P}_{2} \mathrm{O}_{5}\right)$ per hectare, were applied once when sowing according to the local cropping system. The cultivar of winter wheat (Triticum aestivum L.) used in the experiments is 'Changhan 58', which is widely cultivated in the study area. Wheat seeds were sown in $5-\mathrm{cm}$ soil depth with the row spacing of $20 \mathrm{~cm}$ and the seeding rate of $150 \mathrm{~kg} / \mathrm{hm}^{2}$ on 14 September 2006 and 22 September 2007, respectively. Crops were harvested at the end of June in both years. 
Table 1 Treatments of water-N combinations and irrigations

\begin{tabular}{|c|c|c|c|c|c|c|c|c|c|c|c|c|}
\hline \multicolumn{7}{|c|}{ Treatment of water- $\mathrm{N}$ combination } & \multicolumn{6}{|c|}{ Treatment of irrigation in growing period $(\mathrm{mm})$} \\
\hline & No & N1 & $\mathrm{N} 2$ & $\mathrm{~N} 3$ & N4 & N5 & Over-wintering & Turning green & Jointing & Heading & Filling & Whole growing \\
\hline W0 & W0N0 & W0N1 & W0N2 & W0N3 & W0N4 & W0N5 & 0 & 0 & 0 & 0 & 0 & 0 \\
\hline W1 & W1N0 & & $\mathrm{W} 1 \mathrm{~N} 2$ & & & W1N5 & 75 & 0 & 0 & 0 & 0 & 75 \\
\hline W2 & W2N0 & & W2N2 & & & W2N5 & 75 & 75 & 0 & 0 & 0 & 150 \\
\hline W3 & W3N0 & W3N1 & W3N2 & W3N3 & W3N4 & W3N5 & 75 & 75 & 75 & 0 & 0 & 225 \\
\hline W4 & W4N0 & & W4N2 & & & W4N5 & 75 & 75 & 75 & 75 & 0 & 300 \\
\hline W5 & W5N0 & W5N1 & W5N2 & W5N3 & W5N4 & W5N5 & 75 & 75 & 75 & 75 & 75 & 375 \\
\hline
\end{tabular}

\subsection{Methods}

\subsubsection{Plant and soil sampling}

Sampling and measurement procedures were respectively the same in the two growing seasons. Soil water content in each plot was measured at a depth of $300 \mathrm{~cm}$ and at an interval of $20 \mathrm{~cm}$ using the gravimetric method at sowing and harvesting times. Wheat spikes were investigated at a fixed position before harvesting. Grains per spike were measured by harvesting 20 spikes from each plot. Wheat plants in an area of $1 \mathrm{~m}^{2}$ in the center of each plot were harvested for measuring grain yields and determining 1000-grain weight.

\subsubsection{Evapotranspiration (ET) and WUE}

Field ET (mm) was estimated by water balance method:

$$
E T=P+I+\Delta S W S-R-D \text {. }
$$

Where, $P$ is the precipitation amount during the growing season $(\mathrm{mm}) ; I$ is the amount of irrigation $(\mathrm{mm}) ; \triangle S W S$ is the net decrease of soil water storage in the upper soil layer of $300 \mathrm{~cm}$ from the beginning to the end of the growing season $(\mathrm{mm}) ; R$ is the surface runoff (mm); and $D$ is the deep leakage $(\mathrm{mm})$. For the little precipitation and deep groundwater table in this region, $R$ and $D$ were very small and could be neglected here.

Then, the equation for ET can be simplified as Eq. 2.

$$
E T=P+I+\Delta S W S \text {. }
$$

This equation indicates that ET is the sum of precipitation, irrigation and net decrease of soil water storage during the whole growing season.

The equation for soil water storage is given as below:

$$
S W S=h \times a \times \theta \times 10 .
$$

Where $h$ is the soil depth (cm), $a$ is the soil bulk den- sity $\left(\mathrm{g} / \mathrm{cm}^{3}\right)$, and $\theta$ is the soil water content change (\%).

The WUE for wheat in our experiments was calculated by the grain yield divided by the total ET during the whole growing season.

1.3.3 Elasticity index (EI) and relationships with water- $\mathrm{N}$ inputs

When water and $\mathrm{N}$ inputs change linearly or only one factor of them varies, EI can illustrate the relationships between crop yield, water consumption and WUE in two-dimensional coordinates (Liu, 1998). However, if the amounts of water and $\mathrm{N}$ change randomly at the same time, the relationships between crop yield, water and fertilizer inputs can't be presented in two-dimensional coordinates. The yield (Y) and ET should be described as a function of water $\left(x_{1}\right)$ and $\mathrm{N}\left(x_{2}\right)$ inputs in three-dimensional coordinates.

$$
\begin{gathered}
Y=Y\left(x_{1}, x_{2}\right), \\
E T=E T\left(x_{1}, x_{2}\right) .
\end{gathered}
$$

So, EI would be calculated as Eq. 6 (Liu and Zhang, 2007).

$$
E I=\frac{\frac{\partial Y}{\partial x_{2}} \frac{d x_{2}}{d x_{1}}+\frac{\partial Y}{\partial x_{1}}}{\frac{\partial E T}{\partial N} \frac{d x_{2}}{d x_{1}}+\frac{\partial E T}{\partial x_{1}}} \times \frac{E T}{Y}
$$

After selecting a direction of $d x_{2} / d x_{1}$ in the water-N $\left(x_{1}-x_{2}\right)$ plane, the relationships between crop yield, ET and WUE, and the characteristics of which can be analyzed at the thresholds of EI ( 1 or 0$)$. Then, Eq. 6 could be used to describe the optimal range of water and $\mathrm{N}$ coupling based on the observed yield data. Liu et al. (2002) also reported their results using the direction of $d x_{2} / d x_{1}$, which can be represented by the following two directions.

(1) One direction is the line from a local point $\left(x_{1}, x_{2}\right)$ 
to the point $\left(x_{1 \mathrm{~m}}, x_{2 \mathrm{~m}}\right)$ with global maximum yield $\left(Y_{\max }\right)$ :

$$
\frac{d x_{2}}{d x_{1}}=\frac{x_{2}-x_{2 m}}{x_{1}-x_{1 m}} .
$$

The physical meaning of Eq. 7 implies that the global $Y_{\max }$ can be identified when the shortest distance of $x_{1}$ and $x_{2}$ is reached.

(2) The other direction is the greatest gradient direction of the point on the $\mathrm{Y}$ surface:

$$
\frac{d x_{2}}{d x_{1}}=\frac{\partial Y / \partial x_{2}}{\partial Y / \partial x_{1}} .
$$

The physical meaning of Eq. 8 is that the greatest yield increase can be determined at certain levels of $x_{1}$ and $x_{2}$.

Using Eq. 6, the EI in the direction of $d x_{2} / d x_{1}$ can be calculated based on the expression of $d x_{2} / d x_{1}$.

\section{Results}

\subsection{Effects of water and $\mathrm{N}$ coupling on crop yield}

The grain yield elements of winter wheat varied greatly under different levels of water and $\mathrm{N}$ coupling from the over-wintering to the heading period (Figs. 2-4). Under the same irrigation conditions (except for W5), spikes increased with the increase of $\mathrm{N}$ inputs (Fig. 2). Spikes reached the maximum

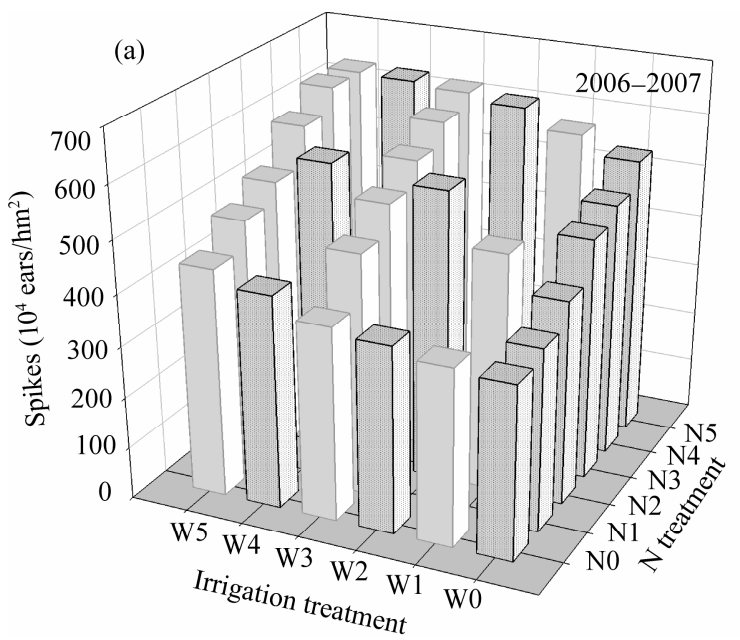

values of $638.125 \times 10^{4}$ ears $/ \mathrm{hm}^{2}$ for the treatment W5N4 in $2006-2007$ and $698.125 \times 10^{4}$ ears $/ \mathrm{hm}^{2}$ for W4N5 in 2007-2008. The variation in grains per spike was similar to that in spikes (Fig. 3). The largest grains per spike in 2006-2007 and 2007-2008 were 38.85 for W5N2 treatment and 41.49 for W3N5 treatment, respectively. The 1000 -grain weight decreased with the increase of $\mathrm{N}$ inputs or irrigation amounts (Fig. 4). The treatment W3N0 in 2006-2007 had the maximum 1000-grain weight value of $45.6 \mathrm{~g}$, while the treatment W5N0 in 2007-2008 had the maximum value of $49 \mathrm{~g}$.

Notably, the yield of winter wheat can be improved using the appropriate amounts of water and $\mathrm{N}$, because we identified a positive relationship between water and $\mathrm{N}$ inputs (Fig. 5). In 2006-2007, as the amount of irrigation increased and the $\mathrm{N}$ levels were between $\mathrm{N} 0$ to $\mathrm{N} 3$, the yield increased significantly. However, when the N levels were between N4 and N5, the yield increased slightly with the increase of irrigation inputs. In 2006-2007, the highest yield of winter wheat $\left(8.87 \mathrm{t} / \mathrm{hm}^{2}\right)$ was obtained for the treatment W3N4 (Table 2 and Fig. 5). The variation trend of winter wheat yield in 2007-2008 was similar to that in 2006-2007, and the highest winter wheat yield in $2007-2008\left(10.09 \mathrm{t} / \mathrm{hm}^{2}\right)$ was also obtained for the treatment W3N4.

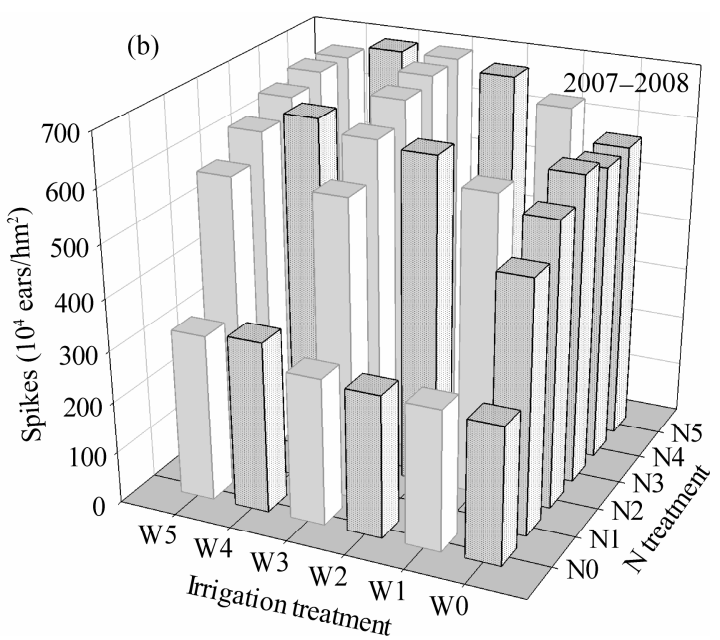

Fig. 2 Effects of water and N coupling on spikes in 2006-2007 (a) and 2007-2008 (b) 

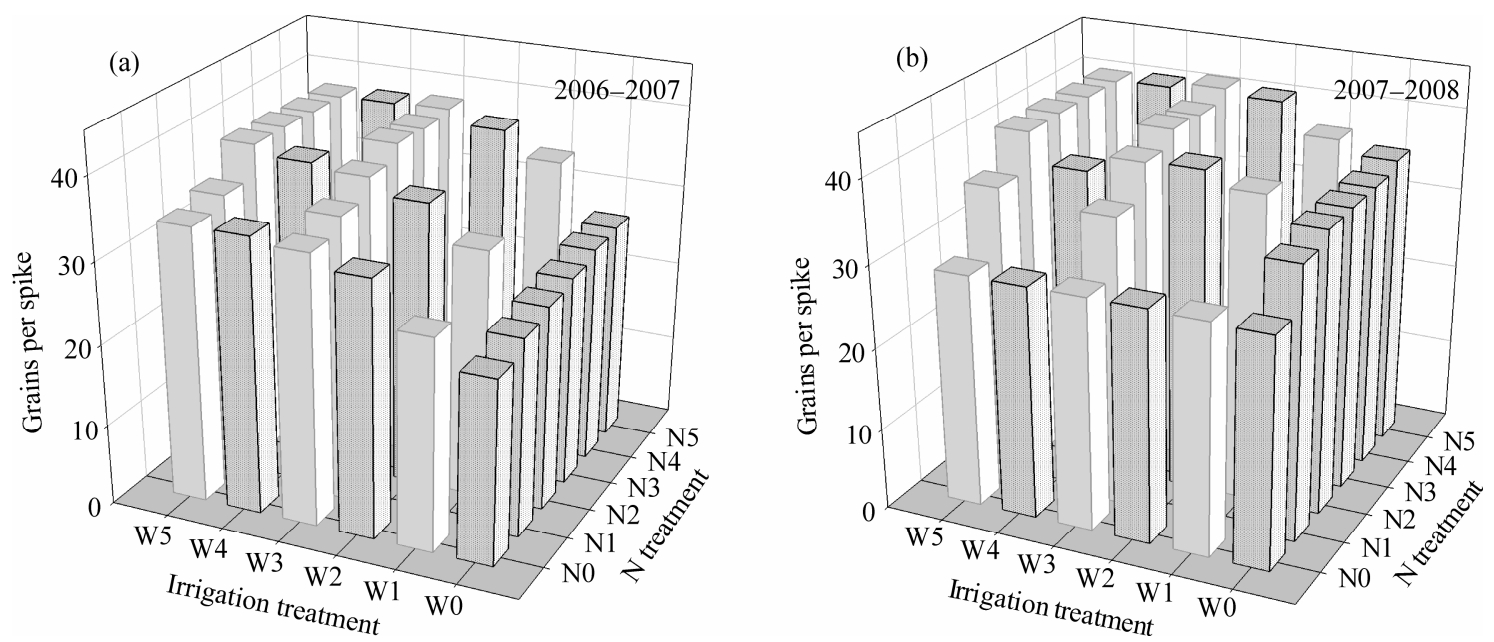

Fig. 3 Effects of water and N coupling on grains per spike in 2006-2007 (a) and 2007-2008 (b)
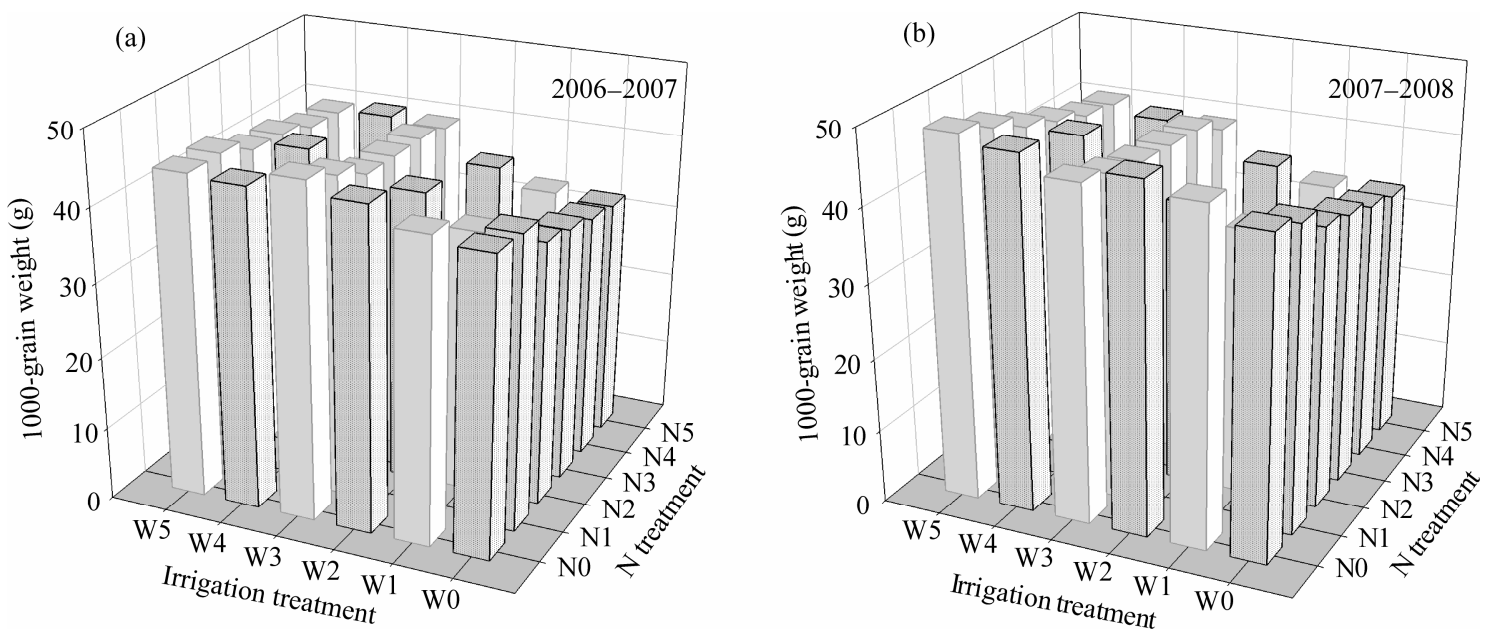

Fig. 4 Effects of water and N coupling on 1000-grain weight in 2006-2007 (a) and 2007-2008 (b)
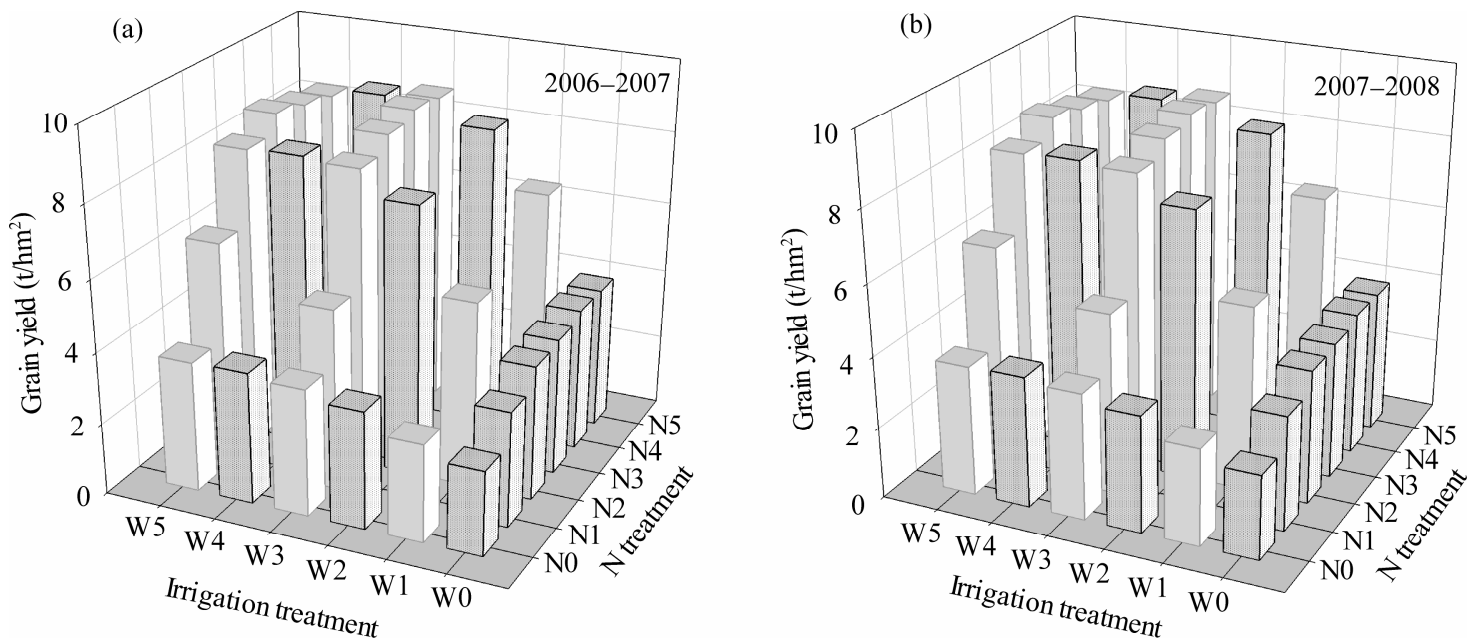

Fig. 5 Effects of water and N coupling on grain yield in 2006-2007 (a) and 2007-2008 (b) 
Table 2 Yield (Y), evapotranspiration (ET) and water use efficiency (WUE) for different water-N combination treatments in 2006-2007 and $2007-2008$

\begin{tabular}{|c|c|c|c|c|c|c|}
\hline \multirow{2}{*}{ Treatment } & \multicolumn{3}{|c|}{ 2006-2007 } & \multicolumn{3}{|c|}{ 2007-2008 } \\
\hline & $\mathrm{Y}\left(\mathrm{t} / \mathrm{hm}^{2}\right)$ & $\mathrm{ET}(\mathrm{mm})$ & WUE $\left(\mathrm{kg} /\left(\mathrm{hm}^{2} \cdot \mathrm{mm}\right)\right)$ & $\mathrm{Y}\left(\mathrm{t} / \mathrm{hm}^{2}\right)$ & $\mathrm{ET}(\mathrm{mm})$ & WUE $\left(\mathrm{kg} /\left(\mathrm{hm}^{2} \cdot \mathrm{mm}\right)\right)$ \\
\hline WONO & 2.38 & 358.73 & 6.64 & 2.91 & 388.29 & 7.49 \\
\hline W0N1 & 3.24 & 366.81 & 8.83 & 4.46 & 396.08 & 11.27 \\
\hline W0N2 & 3.77 & 370.90 & 10.17 & 5.82 & 393.35 & 14.79 \\
\hline W0N3 & 3.84 & 377.03 & 10.18 & 6.33 & 401.59 & 15.76 \\
\hline W0N4 & 4.03 & 382.02 & 10.54 & 6.38 & 400.51 & 15.94 \\
\hline W0N5 & 3.98 & 386.06 & 10.32 & 6.24 & 405.75 & 15.37 \\
\hline W1N0 & 2.75 & 424.33 & 6.47 & 2.92 & 432.57 & 6.74 \\
\hline $\mathrm{W} 1 \mathrm{~N} 2$ & 5.23 & 439.88 & 11.89 & 7.64 & 455.91 & 16.77 \\
\hline W1N5 & 6.49 & 451.23 & 14.39 & 8.13 & 466.58 & 17.42 \\
\hline W2N0 & 3.30 & 472.83 & 6.99 & 3.11 & 484.34 & 6.43 \\
\hline W2N2 & 7.59 & 486.42 & 15.60 & 8.81 & 513.35 & 17.17 \\
\hline W2N5 & 8.07 & 501.30 & 16.09 & 9.76 & 521.30 & 18.73 \\
\hline W3N0 & 3.57 & 509.31 & 7.01 & 3.22 & 543.78 & 5.91 \\
\hline W3N1 & 5.08 & 538.53 & 9.43 & 6.83 & 556.48 & 12.28 \\
\hline W3N2 & 8.29 & 554.62 & 14.94 & 9.32 & 577.50 & 16.13 \\
\hline W3N3 & 8.68 & 558.17 & 15.56 & 10.01 & 581.97 & 17.19 \\
\hline W3N4 & 8.87 & 563.10 & 15.75 & 10.09 & 580.71 & 17.38 \\
\hline W3N5 & 8.73 & 567.16 & 15.40 & 10.00 & 597.21 & 16.74 \\
\hline W4N0 & 3.69 & 552.18 & 6.68 & 3.35 & 593.83 & 5.64 \\
\hline W4N2 & 8.38 & 584.06 & 14.34 & 9.46 & 660.11 & 14.33 \\
\hline W4N5 & 8.61 & 619.60 & 13.89 & 9.85 & 683.02 & 14.42 \\
\hline W5N0 & 3.65 & 600.27 & 6.08 & 3.38 & 632.65 & 5.34 \\
\hline W5N1 & 6.32 & 609.61 & 10.36 & 7.72 & 663.65 & 11.63 \\
\hline W5N2 & 8.32 & 612.46 & 13.58 & 9.47 & 682.79 & 13.87 \\
\hline W5N3 & 8.81 & 614.62 & 14.33 & 10.06 & 694.19 & 14.49 \\
\hline W5N4 & 8.57 & 617.21 & 13.89 & 10.00 & 705.84 & 14.16 \\
\hline W5N5 & 8.37 & 619.52 & 13.50 & 9.67 & 711.52 & 13.59 \\
\hline
\end{tabular}

\subsection{Responses of yield to water and $\mathrm{N}$ coupling}

2.2.1 Analysis of yield responses to water and $\mathrm{N}$ coupling

According to the yields of winter wheat under different water and $\mathrm{N}$ combination conditions, the relationships between yield, water and $\mathrm{N}$ fertilizer inputs in 2006-2007 and 2007-2008 were simulated as Eq. 9 and Eq. 10, respectively.

$Y=1225.569+23.072 W+27.386 N+0.019 W N-0.0451 W^{2}$

$-0.054 N^{2}\left(F=71.679, R^{2}=0.945, P<0.001\right)$,

$Y=1740.825+18.085 \mathrm{~W}+41.811 \mathrm{~N}+0.016 \mathrm{WN}-0.036 \mathrm{~W}^{2}$ $-0.08 N^{2}\left(F=102.788, R^{2}=0.961, P<0.001\right)$.

Where, $Y$ is the yield of winter wheat $\left(\mathrm{kg} / \mathrm{hm}^{2}\right) ; W$ is the irrigation quantity $(\mathrm{mm})$; and $N$ is the $\mathrm{N}$ amount $\left(\mathrm{kg} / \mathrm{hm}^{2}\right)$. These results showed that the simulated yield of winter wheat from Eq. 9 and Eq. 10 agreed well with the observed data in the growing seasons of 2006-2007 and 2007-2008, respectively (Fig. 6).

The regressive equations (Eqs. 9 and 10) from the two-year study suggested: (1) The yield of winter wheat first increased with the increase of water and $\mathrm{N}$ inputs, as evidenced by the positive first order coefficients in the regression equations; and (2) All the quadratic coefficients in the regression equations were negative, indicating a downward parabola and implying that excessive irrigation and $\mathrm{N}$ inputs may result in higher costs and lower yields. 


\subsubsection{Analysis of the marginal yield}

In a multiple regression model, the marginal yield represents the increase in total yield as one variable changes while the other variables remain unchanged (Li et al., 2000). The effects of water and $\mathrm{N}$ inputs on winter wheat yield followed the law of diminishing returns. At this point, the associated amounts of water and $\mathrm{N}$ can be considered the optimal values as shown in Fig. 7. From Fig. 7, we can get two conclusions: (1) The slope of $Y_{\mathrm{N}}$ ' in the normal year (2007-2008) was larger than that in the drought year (2006-2007), which indicated that the amount of $\mathrm{N}$ had a greater effect on winter wheat yield as the amount of water increased; and (2) The slope of $Y_{\mathrm{w}}$ ' in the drought year (2006-2007) was larger than that in the normal year (2007-2008), which showed that the wheat yield was more sensitive to irrigation in the drought year.

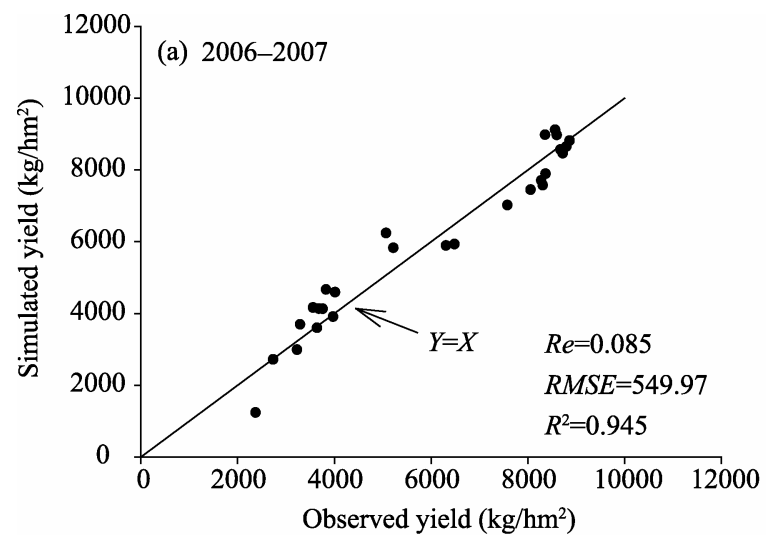

2.2.3 Inputting amounts of water and $\mathrm{N}$ fertilizer for the maximum crop yield

The maximum crop yield scheme shows the input levels of water and $\mathrm{N}$ for achieving the maximum crop yield without considering the costs. In this study, the partial derivatives of water and $\mathrm{N}$ in 2006-2007 and 2007-2008 were calculated based on Eq. 9 and Eq. 10, respectively. In 2006-2007:

$$
\begin{gathered}
\partial Y / \partial W=23.072+0.019 N-0.0902 W \\
\partial Y / \partial N=27.386+0.019 W-0.108 N
\end{gathered}
$$

In 2007-2008:

$$
\begin{gathered}
\partial Y / \partial W=18.085+0.016 N-0.072 W \\
\partial Y / \partial N=41.811+0.016 W-0.16 N
\end{gathered}
$$

When $\partial Y / \partial W$ and $\partial Y / \partial N$ (Eqs. 11-14) are considered to be zero, the amounts of water and $\mathrm{N}$ required for achieving the $Y_{\max }$ in different years can be calculated (Table 3).

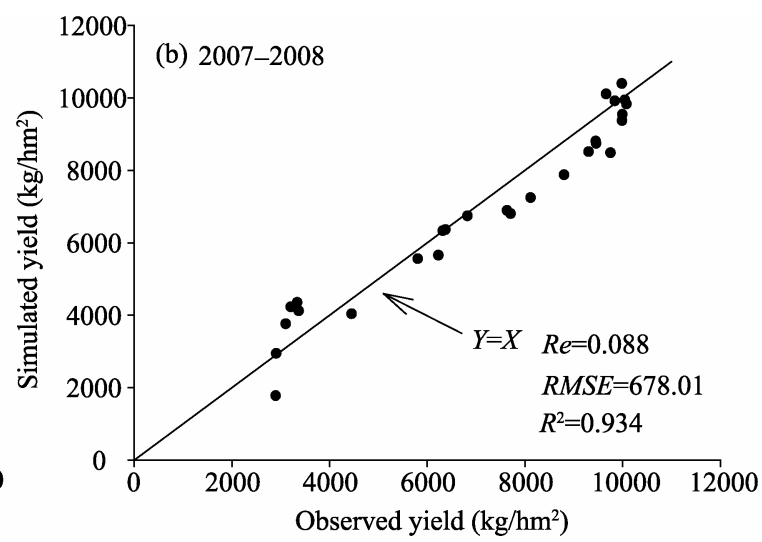

Fig. 6 Relationships between the observed and simulated yields in 2006-2007 (a) and 2007-2008 (b). Y=X, 1:1 line.
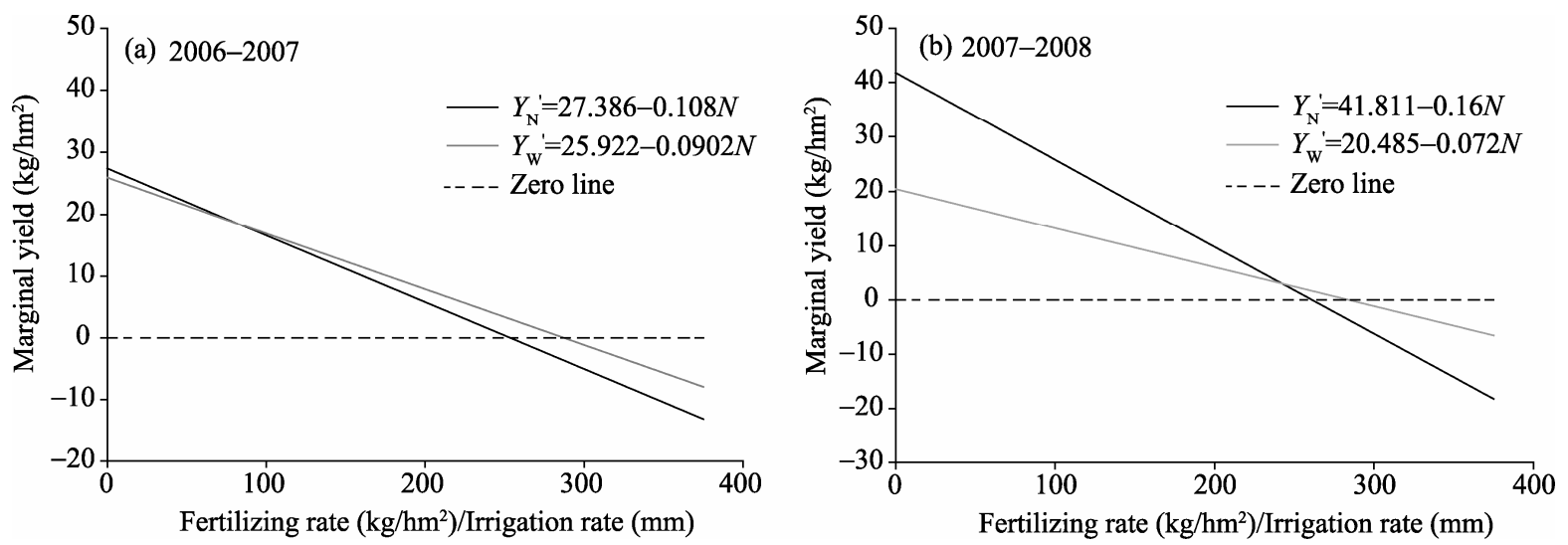

Fig. 7 Relationships between the amounts of irrigation water, N fertilizer and marginal yield in 2006-2007 (a) and $2007-2008$ (b) 
Table 3 Amounts of water and $\mathrm{N}$ inputs for achieving the maximum yield $\left(Y_{\max }\right)$

\begin{tabular}{cccc}
\hline Year & $\begin{array}{c}\text { Irrigation } \\
\text { amount }(\mathrm{mm})\end{array}$ & $\begin{array}{c}\mathrm{N} \text { addition } \\
\left(\mathrm{kg} / \mathrm{hm}^{2}\right)\end{array}$ & $Y_{\max }\left(\mathrm{t} / \mathrm{hm}^{2}\right)$ \\
\hline $2006-2007$ & 321.10 & 310.00 & 9.18 \\
$2007-2008$ & 316.28 & 292.95 & 10.72 \\
\hline
\end{tabular}

\subsection{Optimal coupling domain for water and $\mathrm{N}$ inputs}

Although we have calculated the amounts of water and $\mathrm{N}$ inputs to achieve the maximum winter wheat yield, it is more practical to consider a suitable range for water and $\mathrm{N}$ inputs, i.e. the 'optimal coupling domain' of water and $\mathrm{N}$ inputs. Within this coupling domain, we can determine the water and $\mathrm{N}$ inputs that satisfy the high WUE and crop yield. This would allow our study to have a higher relevance in practical application.

\subsubsection{Response functions of yield and ET to water} and $\mathrm{N}$ input levels

The regression equations representing yield and ET were described by $\mathrm{N}$ and water inputs for 2006-2007 (Eqs. 15 and 16) and 2007-2008 (Eqs. 17 and 18) based on simplified water and $\mathrm{N}$ input levels, and the observed yield and ET values were from Table 2 .

$Y=-3.006+2.553 x_{2}+2.125 x_{1}+0.108 x_{1} x_{2}-0.304 x_{2}^{2}-0.252 \mathrm{x}_{1}^{2}$,

$E T=312.438+7.025 x_{2}+48.425 x_{1}\left(F=433.38, R^{2}=0.973\right.$, $P<0.001)$,

$Y=-3.316+3.953 x_{2}+1.669 x_{1}+0.088 x_{1} x_{2}-0.452 x_{2}^{2}-0.2 x_{1}^{2}$,

$E T=305.236+9.674 x_{2}+58.164 x_{1}\left(F=791.93, R^{2}=0.985\right.$, $P<0.001)$.

In three-dimensional coordinates, the yield was represented by a quadratic paraboloid whereas the ET formed a plane, based on Eqs. 15-18. In 2006-2007, the maximum winter wheat yield was $9.211 \mathrm{t} / \mathrm{hm}^{2}$ when $x_{1}=5.319$ and $x_{2}=5.144$, and the maximum WUE $\left(W U E_{\max }\right)$ of $16.335 \mathrm{~kg} /\left(\mathrm{hm}^{2} \cdot \mathrm{mm}\right)$ was achieved when $x_{1}=3.645$ and $x_{2}=4.658$. With the same method, in 2007-2008, the maximum winter wheat yield of $10.715 \mathrm{t} / \mathrm{hm}^{2}$ was achieved when $x_{1}=5.247$ and $x_{2}=4.880$, and the WUE reached its maximum value of $18.69 \mathrm{~kg} /\left(\mathrm{hm}^{2} \cdot \mathrm{mm}\right)$ with $x_{1}=2.425$ and $x_{2}=4.410$.
2.3.2 Optimal coupling domain for water and $\mathrm{N}$ inputs Equation 6 can be used to delineate an optimal coupling domain for water and $\mathrm{N}$ inputs using our experimental data. Firstly, we considered the line direction using Eq. 7, in search of a global $Y_{\max }$. In 2006-2007, substituting the values of $x_{1 \mathrm{~m}}, x_{2 \mathrm{~m}}$, Eqs. 15-16 and their corresponding derivatives with respect to $x_{1}$ and $x_{2}$ into Eq. 6, and then setting EI equals to 1 (Liu, 1998) resulted in the $x_{1}-x_{2}$ relationship (Fig. 8). The relationship between water and $\mathrm{N}$ levels can be represented by an ellipse, and the edge points of the ellipse represent the local maxima of WUE because EI is always equal to 1 . The value of $d x_{2} / d x_{1}$ at the point of the global $Y_{\max }$ does not exist, so the values of $x_{1}$ and $x_{2}$ can not reach the $Y_{\max }$ point when $E I$ is set to 1 . When the yield reaches its global maximum value, $E I$ equals zero. The values of $x_{1}$ and $x_{2}$ at the $Y_{\max }$ point are shown in Fig. 8. The point representing the $Y_{\max }$ is also shown on the trend line, although it does not exist when $E I=1$. Hence, the ellipse region is surrounded by a series of $Y_{\max }$ points at $E I=0$ and $E I=1$ for different soil water and $\mathrm{N}$ levels. This ellipse region is therefore considered to be the feasible region of water and $\mathrm{N}$ inputs. The lower limit of the feasible region is the point at which the WUE reaches a global maximum value, and the upper limit of the feasible region is the point at which the yield reaches its global maximum value. As shown in Fig. 8, $Y_{\max }$ and $W U E_{\max }$ are located at the two end points of the long axis in the ellipse. The ellipse equations for 2006-2007 and 2007-2008 were shown as Eq. 19 and Eq. 20, respectively. This equation for the ellipse was called the first species ellipse.

$$
0.749 x_{2}^{2}+0.638 x_{1}^{2}-0.071 x_{1} x_{2}-7.027 x_{2}-5.368 x_{1}+28.773=0 \text {, }
$$

$2.01 x_{2}^{2}+0.777 x_{1}^{2}-0.423 x_{1} x_{2}-17.05 x_{2}-3.99 x_{1}+45.744=0$.

Both equations (Eqs. 19 and 20) for 2006-2007 and 2007-2008 had the same form, in which the global $Y_{\max }$ and $W U E_{\max }$ located at the two end points of the long axes in the ellipse, and their gradients, were also similar. This water-N coupling area was found to be similar for both the dry and normal years, which implies that this method is credible.

When selecting the greatest gradient direction of 

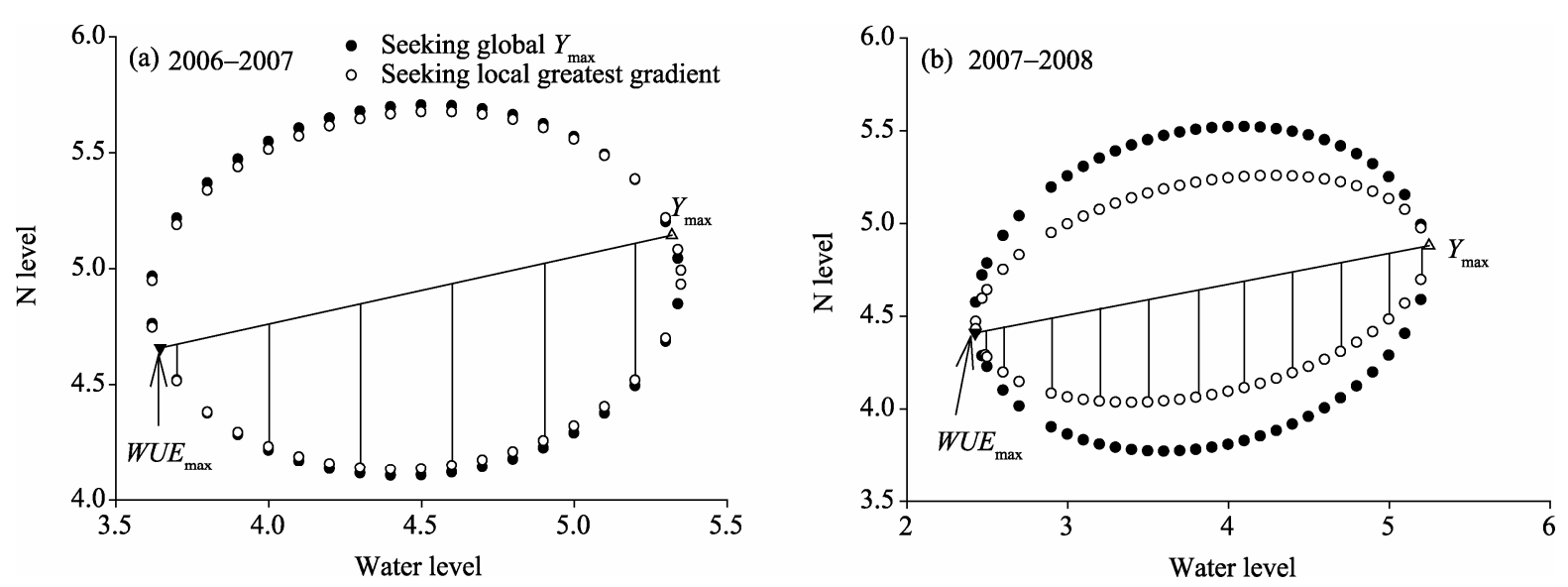

Fig. 8 Optimal coupling domains for water and N inputs in 2006-2007 (a) and 2007-2008 (b)

the point on the Y surface (Eqs. 8), we derived another set of ellipses that were also shown in Fig. 8. The ellipse equations for 2006-2007 and 2007-2008 were represented as Eq. 21 and Eq. 22, respectively. $0.745 x_{2}^{2}+0.589 x_{1}^{2}-0.099 x_{1} x_{2}-6.861 x_{2}-4.794 x_{1}+27.118=0$,

$1.999 x_{2}^{2}+0.378 x_{1}^{2}-0.555 x_{1} x_{2}-16.438 x_{2}-0.322 x_{1}+38.115=0$.

These two equations was of the second species ellipse. Compared with the first species ellipse (used to determine $Y_{\max }$ ), the two end points on the long axis of the second species ellipse still represented $Y_{\max }$ and $W U E_{\max }$, but the length of their short axes were smaller.

As mentioned above, the equation for describing the yield responses to water and $\mathrm{N}$ inputs was a smooth parabola. The global and local maximum yields under each water or $\mathrm{N}$ treatment existed on the parabola. The right end point on the long axis of the ellipse was the projected point for the global and local maximum yields. In other words, the yield reaches its local maxima on the long axis of the ellipse. The left end point on the long axis of the ellipse represented the local maxima of WUE. In practice, it is always desired that increasing the inputs of water and $\mathrm{N}$ results in the maximum increase in yield, and the second species ellipse was constructed to reflect conditions just in this case. Therefore, the lower half of the ellipsoid (the hatched area in Fig. 8) represents the optimal coupling domain for water and $\mathrm{N}$ inputs in practical agriculture of our study area.

\section{Discussion and conclusions}

Water and fertilizer, which restrict or promote the growth of winter wheat, are two key factors relating to crop yield (Shangguan et al., 1999). Some studies have shown that improving irrigation and fertilizer conditions significantly affected the yield of winter wheat (Meng et al., 1998; Li et al., 2000; Li et al., 2005; Kong et al., 2008). Positive effects on wheat yield have been documented for a certain range of water and fertilizer inputs, such that greater amounts of water were matched with higher amounts of fertilizer, and vice versa (Zhao et al., 2009). However, winter wheat yields have also been reported to be decreased when the inputs of water and fertilizer exceeded a certain range ( $\mathrm{Li}$ et al., 2000; Zhang et al., 2005). Similar results were also found in our study.

Spikes, grains per spike and 1000-grain weight are considered to be the three key elements that have the greatest effect on grain yield of winter wheat. Zhao et al. (2009) found that the spikes and 1000-grain weight increased with the increase of irrigation frequencies, while no significant relationship existed between $\mathrm{N}$ inputs and 1000-grain weight. In addition, Li et al. (2005) reported that within a certain inputs range, spikes of winter wheat increased with the increase of water and $\mathrm{N}$ amounts, following the shape of a quadratic parabola under different water conditions. The 1000 -grain weight decreased with the increase of $\mathrm{N}$ inputs under a certain water level, while it was not significantly affected by water inputs when the $\mathrm{N}$ input was fixed. Zhang et al. (2005) found that both 
spikes and grains per spike increased as $\mathrm{N}$ inputs were coupled with a high water level. However, the 1000 -grain weight was negatively correlated to water quantity, and no significant relationship was found between 1000-grain weight and fertilizer inputs.

In our study, spikes increased with the increase of both water quantities and $\mathrm{N}$ inputs. In addition, the variation of grains per spike was similar to that of spikes, which also increased with the increase of water and $\mathrm{N}$ inputs. We also found that the 1000-grain weight decreased with the increase of $\mathrm{N}$ inputs, and there was no significant relationship between 1000-grain weight and increased irrigation levels. Our results, concerning spikes, grains per spike and 1000-grain weight of winter wheat for different amounts of water and $\mathrm{N}$, were different from those reported in other studies. The reason may be the differences in plot scales, and related water and fertilizer conditions.

The equation describing yield responses to water and $\mathrm{N}$ inputs directly reflected the interactions between these factors. In this study, the increase of water and $\mathrm{N}$ levels improved the winter wheat yield and promoted each other, but only to a certain range. Excessive inputs of water and $\mathrm{N}$ not only increased production cost but also decreased crop yield. According to our marginal yield analysis, the effect of water and $\mathrm{N}$ inputs on crop yield was associated with diminishing returns, whereby the winter wheat yield reached its maximum value when the marginal yield was equal to zero. The result was similar to that reported by Zhang et al. (2005), Liu et al. (2000) and Li et al. (2005).

We also observed that the yield response surfaces were quadratic parabolas, while the ET response surfaces were planar in three-dimensional coordinates. These surfaces were obtained from the responsing equations for yield and ET in 2006-2007 (Eqs. 15 and 16) and 2007-2008 (Eqs. 17 and 18). The results showed that, in the drought year, the maximum winter wheat yield was $9.211 \mathrm{t} / \mathrm{hm}^{2}$ for the treatments with $324 \mathrm{~mm}$ irrigation and $310 \mathrm{~kg} / \mathrm{hm}^{2} \mathrm{~N}$ rate, and the highest WUE was $16.335 \mathrm{~kg} /\left(\mathrm{hm}^{2} \cdot \mathrm{mm}\right)$ with $198 \mathrm{~mm}$ irrigation and $274 \mathrm{~kg} / \mathrm{hm}^{2} \mathrm{~N}$ rate. However, in the normal year, the maximum winter wheat yield was $10.715 \mathrm{t} / \mathrm{hm}^{2}$ with the treatments of $318 \mathrm{~mm}$ irrigation and $291 \mathrm{~kg} / \mathrm{hm}^{2} \mathrm{~N}$ input, and the highest WUE was $18.69 \mathrm{~kg} /\left(\mathrm{hm}^{2} \cdot \mathrm{mm}\right)$ corresponding to the treatments with the irrigation of $107 \mathrm{~mm}$ and the $\mathrm{N}$ input of 256 $\mathrm{kg} / \mathrm{hm}^{2}$. The global $Y_{\max }$ and $W U E_{\max }$ were all higher in the normal year than in the drought year.

The useful range of water and fertilizer inputs was directly described by the optimal coupling domain derived from crop yield and WUE. In this domain, when the irrigation amount is below the level required to produce the $W U E_{\max }$, both crop yield and WUE increase with an increased irrigation amount. When the irrigation level is within the range that strikes a balance between the $Y_{\max }$ and $W U E_{\max }$, any additional increase in irrigation amount will cause the crop yield to increase while the WUE to decrease. Consequently, the crop yield and WUE decrease when the irrigation level is higher than the optimal amount for producing the maximum winter wheat yield. These results suggested that the irrigation amount should not exceed $324 \mathrm{~mm}$ for a high winter wheat yield and WUE in the region studied.

In general, the levels of water and fertilizer inputs should be optimized according to different water and fertilizer conditions in a particular region. In regions with limited water resources, the decision about the amount of fertilizer to use should be made by taking into consideration the global $W U E_{\max }$; while in regions with sufficient water resources, this decision should consider the global $Y_{\max }$. Also, the amount of fertilizer required in rain-fed agriculture should be calculated using an optimal water-N coupling domain which accounts for precipitation levels. Moreover, the amount of fertilizer used should be calculated according to the precipitation in a region and its predefined irrigation program. The fertilizer input should be balanced for achieving the best WUE and the highest crop yield.

Considering the two major objectives of crop yield and WUE in dryland agriculture, we determined an optimal coupling domain for applying water and $\mathrm{N}$ to winter wheat in a semi-arid region on the Loess Plateau. This optimal coupling domain directly reflects the best levels of irrigation and $\mathrm{N}$ fertilizer that should be supplied to winter wheat, and also provides a reference for applying reasonable levels of water and fertilizer in practice. 


\section{Acknowledgements}

This work was funded by the National Natural Science Foundation of China (51239009), the National Science and Technology Support Program of China (2011BAD29B05), the Key Discipline Foundation of Water Resources and Hydropower Engineering of Xinjiang Province (XJZDXK-2002-10-05), and the Natural Science Foundation of Shandong Province (ZR2010EM042).

\section{References}

Arnon I. 1975. Physiological principles of dryland crop production. In: Gupta U S. Physiological Aspects of Dry Land Farming. New Delhi: Oxford and IBH Publishing Co., 3-145.

Balasubramanian V, Chari A. 1983. Effect of irrigation scheduling on grain yield and nitrogen use efficiency of irrigated wheat at Kadawa and Bakura, northern Nigeria. Fertilizer Research, 4(3): 201-210.

Cai D T, Wang Y B, Mao Z S, et al. 1994. The effect of sowing date and nitrogen application under different ecosystem on the yield and qualit of the superior wheat variety. Plant Nutrition and Fertilizer Science, 1(1): 74-83.

Chen Z M. 1996. Nitrogen-Yield-Environment. Beijing: China Agriculture and Technology Press, 1-31.

Gajri P R, Prihar S S, Arora V K. 1993. Interdependence of nitrogen and irrigation effects on growth and input-use efficiencies in wheat. Field Crops Research, 31(1-2): 71-86.

Gao Y J, Li S X. 2003. Analysis of the effect of water and nitrogen fertilizer in farmland of Loess Plateau. Plant Nutrition and Fertilizer Science, 9(1): 14-18.

Gu S X, He D M, Cui Y L, et al. 2012. Temporal and spatial changes of agricultural water requirements in the Lancang River Basin. Journal of Geographical Sciences, 22(3): 441-450.

Guo S L, Zhou Y D, Zhang W J, et al. 2003. Effects of long-term application of chemical fertilizer on food production and soil quality attributes. Research of Soil and Water Conservation, 10(1): 6-22.

Hou L K, Zhang Y J, Zhan J Y, et al. 2012. Marginal revenue of land and total factor productivity in Chinese agriculture: Evidence from spatial analysis. Journal of Geographical Sciences, 22(1): 167-178.

Huang M B, Dang T H, Li Y S. 2002. Effect of advanced productivity in dryland farming of the Loess Plateau on soil water cycle. Transactions of the Chinese Society of Agricultural Engineering, 18(6): 50-54.

Huang Z L, Yao D N, Ma C X, et al. 1999. Effects of nitrogen application on yield and quality traits of different wheat varieties. Journal of Anhui Agricultural University, 26(4): 414-418.

Kong D, Yan Y, Duan Y, et al. 2008. Field experiment on growth and yields of winter wheat under different water and nitrogen treatments. Transactions of the Chinese Society of Agricultural Engineering, 24(12): 36-40.

Li F Y, Song L, Guan C Y, et al. 2000. Coupling effect of water and fertilizers on spring wheat yield in semi-arid area of western Liaoning Province. Chinese Journal of Applied Ecology, 11(4): 535-539.

Li J, Shao M A, Zhang X C. 2004. Simulation of water potential productivity of winter wheat and soil water dynamics on rainfed highland of the Loess Plateau. Journal of Natural Resources, 19(6): 738-746.

Li Y B, Zhen L M, Liao S H, et al. 2005. Effects of different patterns of irrigation and $\mathrm{N}$ application on grain yield and utilization ratio of water and nutrient of winter wheat in Beijing suburb. Journal of Triticeae Crops, 25(2): 51-56.

Liu W Z. 1997. An essential requirement of marginal analysis method for calculating farmland water inputs with the maximum profits in water-saving irrigation. Journal of China Agricultural University, 2(Supl.): 121-125.

Liu W Z. 1998. Dynamic interrelations of crop production, water consumption and water use efficiency. Journal of Natural Resources, 13(1): 23-27.

Liu W Z, Li Y S, Li S X. 2002. Graphical presentation and their characteristics of the coupled zones for optimal supplies of water and nutients to crops. Transactions of the Chinese Society of Agricultural Engineering, 18(6): 1-3.

Liu W Z, Zhang X C. 2007. Optimizing water and fertilizer inputs using an elasticity index: a case study with maize in the loess plateau of China. Field Crops Research, 100(2-3): 302-310.

Liu Z X, Zhen Z P, Wang J. 2000. Effect of interaction between water and fertilizer on wheat and maize semiarid region of western Liaoning. Chinese Journal of Applied Ecology, 11(4): 540-544.

Meng Z J, Jia D L, Wu H Q, et al. 1998. Mathematical model of water fertilizer interaction for water saving and high yield winter wheat in east area of Henan province. Transactions of the Chinese Society of Agricultural Engineering, 14(1): 86-90.

Miao G Y, Yin J, Gao Z Q, et al. 1997. Study on the combined effects of simulated rainfalls and nitrogen treatments on the yield and soil moisture dynamic change of rain-fed winter wheat. Acta Agronomica Sinica, 23(3): 263-270.

Sandhu K S, Arora V K, Chand R. 2002. Magnitude and economics of fertilizer nitrogen response of wheat in relation to amount and timing of water inputss. Experimental Agriculture, 38(1): 65-78.

Shangguan Z P, Liu W Z, Xu X B, et al. 1999. Interactive effects of water and fertilizer on yield of winter wheat in dryland. Research of Soil and Water Conservation, 6(1): 103-106.

Sharma B D, Kar S, Cheema S S. 1990. Yield, water use and nitrogen uptake for different water and $\mathrm{N}$ levels in winter wheat. Fertilizer Research, 22(2): 119-127.

Sharma B D, Jalota S K, Kar S, et al. 1992. Effect of nitrogen and water uptake on yield of wheat. Fertilizer Research, 31: 5-8.

Shen R K, Wang K, Zhang Y F, et al. 2001. Field test and study on yield, water use and $\mathrm{N}$ uptake under varied irrigation and fertilizer in crops. Transactions of the Chinese Society of Agricultural Engineering, 17(5): 35-38. 
Tang K L. 1999. Characteristics and perspectives on scientific discipline of soil erosion and soil and water conservation in China. Research of Soil and Water Conservation, 6(2): 2-7.

Tang S H, Yang G H. 1994. Simulated study of the relationship among yield of winter wheat, water and fertilizer application in dryland. Agricultural Research in the Arid Areas, 12: 69-73.

Wang D S. 1995. Controlling Technique and Theories on Fertilizer \& Water in Dry Farmland. Beijing: China Agricultural Scientech Press, $3-50$.

Wu D T, Li H M, Jiao X Y, et al. 2001. Relationship between water and fertilizer for wheat and effect on wheat yield in rainfed field of Loess Plateau. Transactions of the Chinese Society of Agricultural Engineering, 17(5): 39-42.

Xie X Q. 2001. A study on water cycle in agro-ecosystem and relationship between crops and water. Chinese Journal of Eco-Agriculture, 9(1): 9-12.

Zhai B N, Li S X. 2003. Effect of water and nitrogen cooperation on winter wheat yield and quality. Plant Nutrition and Fertilizer Science, 9(1): $26-32$.

Zhai B N, Li S X. 2005. Study on the key and sensitive stage of winter wheat respones to water dan nitrogen coordination. Scientia Agriculutura Sinica, 38(6): 1188-1195.

Zhang F X, Zhou M Y, Xu H P, et al. 2005. Effects of water and fertilizer coupling on growing and yield of winter wheat. Journal of Water Resources and Architectural Engineering, 3(2): 22-24.

Zhao X F, Wang L J, Li R Q, et al. 2009. Effect of irrigation times and nitrogen application rate on population dynamics and grain yield of winter wheat. Journal of Triticeae Crops, 29(6): 1004-1009.

Zhen R T, Liu Y F. 1995. Effects of water and fertilizer on crop yield and their quota drafted. Irrigation and Drainage, 14(2): 8-13.

Zhu Z L. 2000. Loss of fertilizer N from plants-soil system and the strategies and techniques for its reducion. Soil and Environmental Sciences, 9(1): 1-6. 